\title{
Invited Response on: Reply to Invited Discussion on-The Bovine Pericardium Matrix in Immediate Implant-Based Breast Reconstruction
}

\author{
Kamran Khoobehi ${ }^{1}$ (D)
}

Received: 6 January 2021 / Accepted: 11 February 2021/Published online: 15 March 2021

(C) Springer Science+Business Media, LLC, part of Springer Nature and International Society of Aesthetic Plastic Surgery 2021

Level of Evidence $V$ This journal requires that authors assign a level of evidence to each article. For a full description of these Evidence-Based Medicine ratings, please refer to the Table of Contents or the online Instructions to Authors www.springer.com/00266.

The response [1] from the author is much appreciated to clarify the consent. The author did get consent for the procedure and for use of the bovine pericardium.

The issue of animation deformity is not limited to patients with capsular contracture, but all submuscular implant reconstruction patients experience that to some degree. The new approach of prepectoral placement and fat grafting as the author mentioned limits the animation. The authors' explanations are much appreciated.

\section{Compliance with Ethical Standards}

Conflict of interest The author declares that they have no conflict of interest.

Human and Animal Rights This article does not contain any studies with human participants or animals performed by any of the authors.

\section{Reference}

1. Castagnetti F, Bertani C, Foroni M et al (2021) Reply to invited discussion on: the bovine pericardium matrix in immediate implant-based breast reconstruction. Aesth Plast Surg. https://doi. org/10.1007/s00266-020-02114-1

Publisher's Note Springer Nature remains neutral with regard to jurisdictional claims in published maps and institutional affiliations.
Kamran Khoobehi

khoobehi@aol.com

1 Louisiana State University, 3901, Veterans Blvd Metairie, Baton Rouge, LA 70803, USA 